\title{
Childhood Adversities Associated with Eating Disorders Reported by Adults
}

\author{
Veera Sillanpää1, Kari Mattila1,2, Markku Sumanen'1 \\ ${ }^{1}$ Department of General Practice, Medical school, University of Tampere, Tampere, Finland \\ ${ }^{2}$ Centre for General Practice, Pirkanmaa Hospital District, Tampere, Finland \\ Email: markku.sumanen@uta.fi
}

Received 21 September 2015; accepted 18 October 2015; published 21 October 2015

Copyright $(\underset{0}{ } 2015$ by authors and Scientific Research Publishing Inc.

This work is licensed under the Creative Commons Attribution International License (CC BY). http://creativecommons.org/licenses/by/4.0/

(c) (i) 0 pen Access

\begin{abstract}
Background: It has been suggested that childhood events increase the risk of suffering from an eating disorder (ED) in adolescence or young adulthood. Our study here aimed at investigating whether there was an association between stressful childhood events and eating disorders later in life. Methods: Our population-based study was a part of the HeSSup (The Health and Social Support) postal survey in 2003, a follow-up survey with a random sample of working-aged subjects drawn from the Finnish Population Register in 1998. Participants in this study reported having been suffering from ED $(\mathrm{N}=374)$, while controls $(\mathrm{N}=18,639)$ reported no history of eating disorder in the questionnaire both in 1998 and 2003. The questionnaire included six questions related to childhood adversities. Results: Each childhood stressor increased the risk of developing ED cumulatively (one adversity OR 1.7 versus all six OR 8.3). Intrafamiliar conflicts (OR 2.0), being afraid of a family member (OR 1.5) or long-term illnesses in the family (OR 1.4) increased the ED-risk statistical significantly. Conclusion: Children exposed to stress are more likely to suffer from eating disorders as adults than those not exposed.
\end{abstract}

\section{Keywords}

Childhood Adversities, Stressful Life Events, Eating Disorders, Anorexia Nervosa, Bulimia Nervosa

\section{Introduction}

Anorexia nervosa (AN) with estimated prevalence of $0.2 \%-0.9 \%$ and bulimia nervosa (BN) with $0.5 \%-4.5 \%$ of sufferers are the most well-known forms of eating disorders (ED) [1]. Others include, for example, binge eating disorder (BED), with a prevalence of approximately $2 \%$ - 3\% [2]. The highest risk for developing anorexia is between ages 14 and 19 years, and for bulimia, it is between ages 17 and 21 years [3]. 
EDs are markedly more common among women than men [4] [5]. They are also more prominent among whites than other ethnic groups [5]. One reason behind this has been assumed to be the fact that white women consider an ideal body shape to be thinner than Latinas and black women [6]. There have been attempts to show that socioeconomic status influences the development of ED but all such studies have failed to establish a connection [7]. Cases of ED have been found across almost all communities where research has been conducted.

Psychological [8] and environmental factors such as physical abuse, poorly functioning interpersonal relationships with parents, family being on a specific diet and family's critical comments regarding one's eating habits all seem to influence the onset of eating disorders [9]. Being susceptible to illness or disease is individual, and both hereditary and environmental factors affect it [10] [11].

Prior research suggests that adverse childhood events increase the risk of suffering from alcoholism, depression, cardiovascular diseases, migraine and asthma [12]-[16]. It has also been suggested that adverse childhood events increase the risk of suffering from an ED in adolescence or young adulthood [17].

It may be speculated that the more adverse childhood events an individual has had the greater is the risk for an eating disorder later in life. According to our knowledge, cumulative effects of childhood adversities on EDs have not been studied before. The study here aims at establishing whether there is a connection between adverse childhood events and ED.

\section{Method}

\subsection{Subjects}

The Health and Social Support Study (HeSSup) is a retrospective cohort study into childhood predictors of adult psychosocial health in a Finnish general population sample. The HeSSup population comprised a random sample of 64,797 individuals drawn from the Finnish Population Register in four age groups: 20 - 24, 30 - 34, 40 44 and 50 - 54 years. The survey was carried out by postal questionnaire in 1998. Forms were returned by 25,895 individuals (response rate 40\%). A follow-up questionnaire was sent in 2003 to all those who responded to the first inquiry. A total of 19,319 individuals responded to it (response rate $75 \%$ ), and this study here made use of these latter responses.

Young women and elderly men were found to be the most active survey respondents [18] while those less active included younger men, elderly women, those with less education, the divorced, the widowers, the unemployed and those on disability pension. Data from the 1998 HeSSup survey were compared with national registers, and a non-response rate analysis was made [18] [19]. Physical health differences between respondents and ordinary citizens appeared to be small with survey subjects thus being fairly well representative of the overall Finnish population.

In the structured questionnaire, the participants were asked an eating disorders-related survey question: "Has a doctor ever told you that you have or have had an eating disorder (anorexia, bulimia)?” Alternative replies were “yes" or "no". Those who answered “yes” in 2003 were classified as persons with a history of an eating disorder. All in all, the data included 374 persons with an eating disorder (Figure 1).

\subsection{Controls}

The control group was formed out of persons who responded "No" to the question about eating disorders (n = 18,945). This group was further narrowed down to include only those who had not reported having suffered from an eating disorder in the original 1998 survey. The control group thus comprised individuals who had reported both in 1998 and 2003 that they were not suffering or had not previously suffered from an eating disorder. A total of 18,639 persons thus formed the control group.

\subsection{Measures}

The subjects were asked to recall their childhood adversities in terms of the following structured questions: "Did your parents divorce?”, “Did your family have long-lasting financial difficulties?”, "Did serious conflicts arise in your family?”, "Were you often afraid of some member of your family?”, "Was someone in the family seriously or chronically ill?”, "Did someone in the family have problems with alcohol?” The alternative answers were "yes”, "no" or "I do not know". Those having answered "Yes” were analysed as one group and those having responded either "no” or “don’t know”/“can’t say” were classified as another group. 


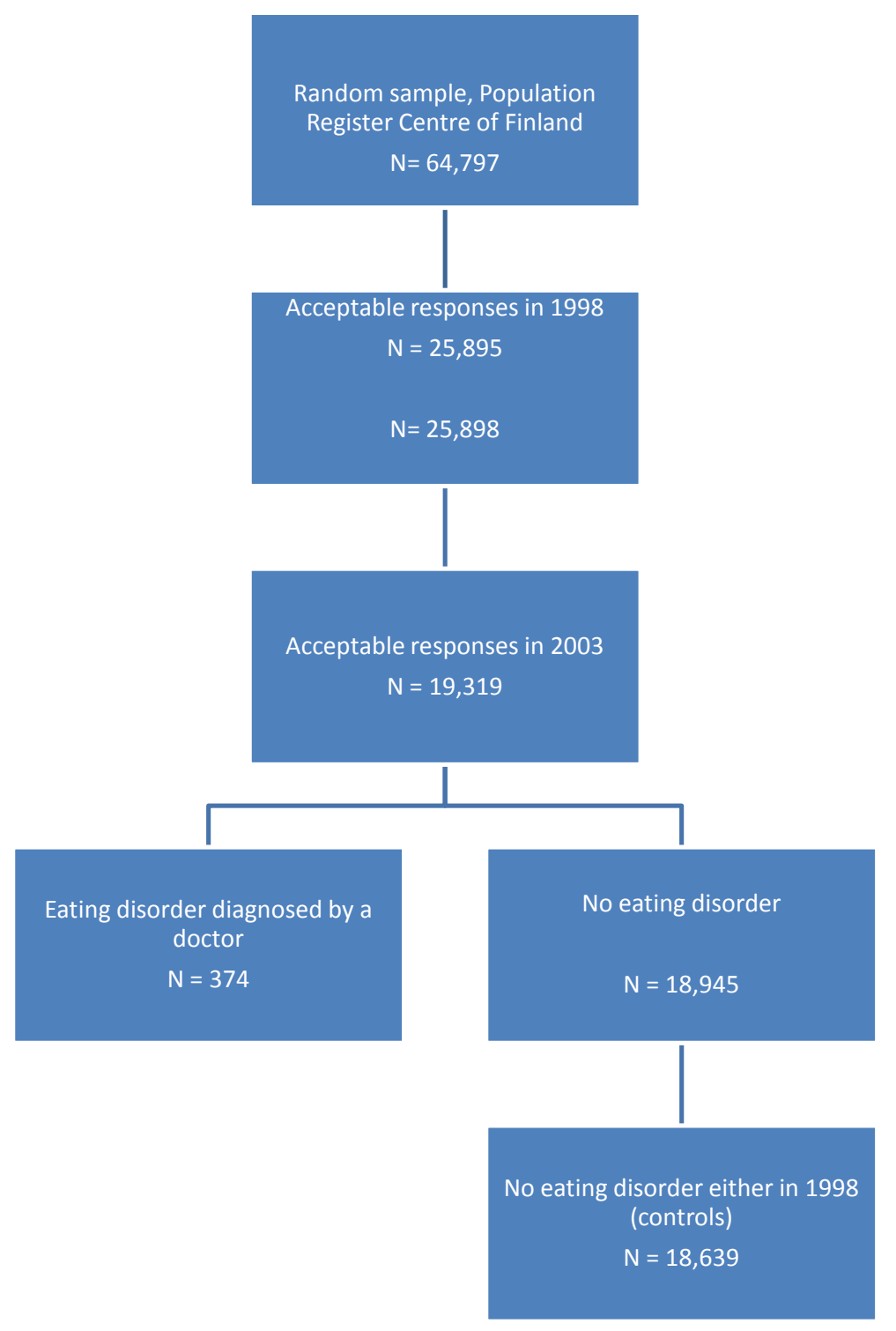

Figure 1. Flow chart description of research data.

A sum variable containing all six sections related to childhood stressors was also built from childhood adversities. With the help of the sum variable the total number of "yes" answers of the subjects was calculated.

Subjects were classified into four age groups: 25 - 29, 35 - 39, 45 - 49 and 55 - 59-year-olds. For the logistic regression analysis, they were further divided into two groups: those under 40 years and those aged 40 or older.

Marital status was classified into three groups: the single and those having a relationship while the "others" included the divorced, the separated and the widowed. Education was classified as "high" for those who had completed high school, and "low" for those who had not. Beck's depression inventory (BDI) was used in assessing whether the respondents suffered from depression [20]. The depression variable was classified into two standardized categories, under 19 points and 19 or more points. The latter group was estimated to suffer from clinically significant depression.

Body Mass Index (BMI) was calculated on the basis of the self-reported heights and weights of the respondents. BMI was then classified into three categories: BMI $<18.5 \mathrm{~kg} / \mathrm{m}^{2}, 18.5-29.9 \mathrm{~kg} / \mathrm{m}^{2}$ and $\geq 30.0 \mathrm{~kg} / \mathrm{m}^{2}$. BMI was considered normal when within the range $18.5-29.9 \mathrm{~kg} / \mathrm{m}^{2}$ whereas those with BMI of 30 or more were assessed as obese.

Smoking status was classified into two categories: non-smokers and regular smokers. Last group included 
also those who had stopped smoking. Alcohol use was charted with a question "In the past 12 months, have you ever passed out due to drinking too much alcohol?” Alternative answers included "never”, "once”, "2 - 3 times”, "4 - 6 times" and "7 times or more". The variable was further classified into two categories. The first group was formed of those, who had never passed out due to alcohol use during the past year, and all the others formed the second group, i.e. persons who had passed out due to their alcohol use at least once during the past year.

\subsection{Statistics}

The statistical significance of differences between the target groups and the controls were tested by $\chi^{2}$ test. Odds ratios (OR) with $95 \%$ confidence intervals (CI) were calculated by logistic regression analysis to measure the risk of belonging to an eating disorder group. Analyses were made using the SPSS system for Windows, release 20.0 .

All participants were asked to sign a consent form to gather follow up data and in order to search Finnish health registers for their data. The joint ethics board of the University of Turku and Turku University Hospital assessed that no medical ethical approval was required to conduct the HeSSup research.

\section{Results}

The characteristics of the eating disorder and control groups are presented in Table 1. EDs were most common among the women, the young, and the depressed. The proportion of persons living in a relationship is smaller among those reporting an ED than among controls.

Depression was associated with a seven-fold risk of reporting an ED. The risk was also greater for women, those living without a partner, the young, and those who had passed out due to alcohol consumption during the past year. On the contrary, smoking and having a higher education were not associated with a risk of reporting an ED (Table 2).

Among women intrafamiliar conflicts and a family member's long-term illness had an association with ED. Among men only economic difficulties were associated with ED. When both genders are analysed together intrafamiliar conflicts, being afraid of a family member and a family member's long-term illness were associated with ED (Table 3).

Accumulation of childhood adversities was associated with ED (Table 4). The more adversities individuals had experienced in their childhood, the greater the association. Accumulation of all inquired adversities to an individual was more than eight times more common in the eating disorder than the control group. Differences between the groups were statistically significant.

\section{Discussion}

Childhood stressors and ED have been found to be linked. Those having experienced multiple childhood adversities had more often been diagnosed with eating disorder than those who had experienced none or only few adversities. The association is stronger the more accumulated adversities there have been in an individual's life. Prior research has already found the connection between childhood adversities and eating problems [7] [21]-[23], maladaptive paternal behaviour [17], childhood sexual abuse [24] as well as environmental factors [9]. Based on the present study, intrafamiliar conflicts, being afraid of a family member and a family member's long-term illness can be added to the list. From the separate events, intrafamiliar conflicts seem to be the ones that increase the risk of suffering from ED the most.

Those reporting an eating disorders are mostly women, which is in line with earlier research findings [4]. Eating disorders were equally common among those who responded to the questionnaire than their estimated prevalence among the general Finnish population [25]. The study here was likewise in accordance with prior research in that no association has been found between the occurrence of ED and level of education [7].

According to our findings, those reporting an eating disorder also reported depression more than controls, which is in accordance with prior research findings [26]. It is possible that these participants recall better any negative life events and thus report more often than the controls that they suffer from ED. Respondents who had recovered from ED and were not depressed at the time of responding to the survey may also forget of having suffered from ED and thus omit reporting it. These kinds of memory lapses cannot be taken into account when analysing responses. 
Table 1. Characteristics of the respondents based on gender, age, marital status, education, weight, smoking, passing out due to alcohol consumption and degree of depression in the eating disorder and control groups.

\begin{tabular}{|c|c|c|c|c|c|}
\hline & \multirow{2}{*}{\multicolumn{2}{|c|}{$\begin{array}{l}\text { Eating disorder } \\
(\mathrm{n}=367-374)^{*}\end{array}$}} & \multirow{2}{*}{\multicolumn{2}{|c|}{$\begin{array}{c}\text { Control group } \\
(\mathrm{n}=18,300-18,639)^{*}\end{array}$}} & \multirow[b]{3}{*}{$p$-value } \\
\hline & & & & & \\
\hline & $\mathrm{n}$ & $\%$ & $\mathrm{n}$ & $\%$ & \\
\hline Gender & & & & & $<0.001$ \\
\hline Female & 309 & 82.6 & 11,364 & 61.0 & \\
\hline Male & 65 & 17.4 & 7275 & 39.0 & \\
\hline Age group (years) & & & & & $<0.001$ \\
\hline $25-29$ & 141 & 37.7 & 4647 & 24.9 & \\
\hline $35-39$ & 77 & 20.6 & 4284 & 23.0 & \\
\hline $45-49$ & 77 & 20.6 & 4653 & 25.0 & \\
\hline $55-59$ & 79 & 21.1 & 5055 & 27.1 & \\
\hline Marital status & & & & & $<0.001$ \\
\hline Single & 101 & 27.1 & 2853 & 15.4 & \\
\hline In a relationship & 214 & 57.4 & 13,914 & 75.0 & \\
\hline Other & 58 & 15.5 & 1792 & 9.7 & \\
\hline Education & & & & & 0.530 \\
\hline Low & 152 & 40.8 & 7858 & 42.4 & \\
\hline High & 221 & 59.2 & 10,687 & 57.6 & \\
\hline BMI (kg/m²) & & & & & 0.005 \\
\hline$<18.5$ & 11 & 3.0 & 258 & 1.4 & \\
\hline $18.5-29.9$ & 297 & 80.7 & 16,028 & 85.3 & \\
\hline$\geq 30.0$ & 60 & 16.3 & 2502 & 13.3 & \\
\hline Smoking & & & & & 0.060 \\
\hline Non-smoker & 146 & 39.0 & 8185 & 43.9 & \\
\hline Smoker & 228 & 61.0 & 10,454 & 56.1 & \\
\hline Passed out due to alcohol & & & & & $<0.001$ \\
\hline Never & 294 & 78.6 & 15,957 & 85.6 & \\
\hline At least once & 80 & 21.4 & 2682 & 14.4 & \\
\hline BDI & & & & & $<0.001$ \\
\hline$<19$ points & 283 & 77.1 & 17,590 & 96.1 & \\
\hline$\geq 19$ points & 84 & 22.9 & 710 & 3.9 & \\
\hline
\end{tabular}

*Every respondent did not answer all questions. 
Table 2. Association between personal characteristics and eating disorders. Statistically significant differences are presented in bold.

\begin{tabular}{|c|c|c|}
\hline & OR (95\% CI) & $p$-value \\
\hline Depression & & $<0.001$ \\
\hline Beck $<19$ & 1 & \\
\hline Beck $\geq 19$ & $7.34(5.70$ - 9.49) & \\
\hline Gender & & $<0.001$ \\
\hline Male & 1 & \\
\hline Female & $3.04(2.34-3.98)$ & \\
\hline Marital status & & $<\mathbf{0 . 0 0 1}$ \\
\hline In a relationship & 1 & \\
\hline Single or others & $2.20(1.79-2.71)$ & \\
\hline Passed out due to alcohol & & $<0.001$ \\
\hline Never & 1 & \\
\hline At last once & $1.62(1.26-2.08)$ & \\
\hline Age group & & $<\mathbf{0 . 0 0 1}$ \\
\hline$\geq 40$ years & 1 & \\
\hline$<40$ years & $1.52(1.23-1.87)$ & \\
\hline Smoking & & 0.060 \\
\hline Non-smoker & 1 & \\
\hline Smoker & $1.22(0.99-1.50)$ & \\
\hline Education & & 0.530 \\
\hline Low & 1 & \\
\hline High & $1.07(0.87-1.32)$ & \\
\hline
\end{tabular}

Table 3. Association between childhood adversities and eating disorders. Statistically significant differences are presented in bold.

\begin{tabular}{|c|c|c|c|c|c|c|}
\hline & Female $(n=309)$ & & Male $(n=65)$ & & All $(n=374)$ & \\
\hline & OR (95\% CI) & $p$-value & OR (95\% CI) & $p$-value & OR (95\% CI) & $p$-value \\
\hline Parental divorce & $1.12(0.84-1.50)$ & 0.424 & $0.66(0.30-1.43)$ & 0.292 & $1.06(0.81-1.38)$ & 0.684 \\
\hline Economic difficulties & $0.89(0.68-1.17)$ & 0.407 & $1.83(1.07-3.15)$ & 0.028 & $1.02(0.80-1.29)$ & 0.898 \\
\hline Intrafamiliar conflicts & $2.20(1.64-2.95)$ & $<\mathbf{0 . 0 0 1}$ & $1.20(0.61-2.38)$ & 0.594 & $2.01(1.54-2.63)$ & $<0.001$ \\
\hline Being afraid of a family member & $1.34(0.99-1.81)$ & 0.056 & $1.72(0.83-3.57)$ & 0.148 & $1.46(1.11-1.93)$ & 0.007 \\
\hline Long-term illness of a family member & $1.31(1.03-1.67)$ & 0.029 & $1.66(1.00-2.77)$ & 0.052 & $1.37(1.01-1.70)$ & 0.005 \\
\hline Alcohol problem of a family member & $1.09(0.83-1.44)$ & 0.547 & $1.07(0.57-2.00)$ & 0.843 & $1.12(0.87-1.44)$ & 0.374 \\
\hline
\end{tabular}

Table 4. Association between cumulative childhood adversities and eating disorders. Statistically significant differences are presented in bold.

\begin{tabular}{|c|c|c|}
\hline & OR (95\% CI) & $p$-value \\
\hline No adversity & 1 & \\
\hline 1 adversity & $1.68(1.24-2.73)$ & 0.001 \\
\hline 2 adversities & $2.10(1.51-2.92)$ & $<0.001$ \\
\hline 3 adversities & $3.31(2.37-4.63)$ & $<0.001$ \\
\hline 4 adversities & $3.33(2.28-4.86)$ & $<0.001$ \\
\hline 5 adversities & $3.48(2.16-5.61)$ & $<0.001$ \\
\hline 6 adversities & $8.31(4.20-16.46)$ & $<0.001$ \\
\hline
\end{tabular}


Respondents' year of birth was inquired about in the survey whereas it is not known when any of the inquired events occurred. Thus it is not known how old the subjects where when faced with the reported childhood adversities and thus this study cannot distinguish those subjects having experienced childhood adversities during the sensitive period from the other participants [27] [28]. It is possible that they were more prone to stress so any adverse events during those periods of time might have had a greater influence during their later life.

Subjects with ED and controls differed from each other with regard to age. Largest category of respondents among those reporting eating disorders were the youngest, while controls were evenly divided between all age groups. EDs occur typically in young people [3]. They may recall a recent or still active disease better than other respondents. Because the question inquiring about ED inquired about current or prior eating disorders, it would have been probable that the occurrence had been greater in older age groups due to summation. In findings of this study, however, the occurrence of ED did not increase in older age groups. On the other hand, it is probable that EDs were not previously diagnosed as frequently as nowadays.

\subsection{Strengths}

HeSSup (The Health and Social Support) survey was a research study with a sample of randomly selected Finns. Respondents were thus not selected into the study based on their possible contacts with primary or specialist care services, which means that our data describe eating disorders on a population-based level. Based on non-response bias analysis, the research data are in accordance with general Finnish population and the respondents were not specifically selected to the survey [18] [19]. Thus, research findings can be generalized to the entire Finnish population. Internationally, the $75 \%$ response rate was excellent.

To ensure good repeatability, the survey is described in detail. In an effort to minimize confidence error, confidence intervals and statistical significance were used. The confidence intervals of the results derived via logistic regression analysis were small, which points to the similarity of the respondents. Deviation among respondents was small. Effort was made to control the confounding factors by adjusting age, gender and degree of depression.

To confirm the reliability of responses regarding childhood adversities, the Cohen's kappa coefficient $(\kappa)$ was used to assess associations between the 1998 and 2003 questionnaires. $\kappa$ varied between 0.621 and 0.903 among participants [15].

\subsection{Limitations}

The question inquiring about eating disorders did not differentiate between types of ED. It is thus entirely possible that childhood stress factors influence some type of ED but not all.

Error sources, which cannot be influenced while doing the research, are always possible in surveys. Respondents may have understood a question in various different ways due to which answers may be distorted. Surveys are always based on participants' recall-and experience-dependent answers. Due to this reason, the authenticity of responses to different questions cannot be directly compared to each other. Even though the survey questionnaire emphasizes the importance of a doctor having diagnosed the ED, it is still possible that a part of the respondents understood the concept of ED in a different manner than what the researchers intended. A person may think that they suffer from ED due to being overweight. Assessed internationally, the Finns answer freely even to fairly personal questions, and the resulting findings can be thus regarded as reliable and generalizable.

The question concerning childhood adversities was not time-limited. It is thus possible that for some respondents childhood signifies primary school, while for others childhood ends when one turns 18 years old, and for yet another group of respondents it ends with the moving out from parental home. Furthermore, for some respondents such an amount of time may have elapsed since their childhood that they may not recall all events from that era or they misremember them. Both study and control groups may include such respondents thus reducing the possibility of research bias.

Our findings on alcohol may also be regarded as a limitation in this study. Passing out due to alcohol represents quite an extreme use of alcohol. We do not have the information on the standard units of alcohol consumed per time.

\section{Conclusions}

Childhood adversities have been found to be associated to the onset of several diseases. It is known today that 
also eating disorders are among these conditions. The more accumulated adversities an individual has experienced in their childhood, the stronger the connection is.

In the future, it might be best to concentrate on those children and young adults having experienced several adversities during their childhoods. By supporting their families, the onset of disease might be prevented or at least its degree of severity reduced. EDs are a long-term illness for many, and some never recover entirely. The onset of disease takes place early in life, at which time it often has negative consequences in one's studies, in selecting a vocation and building a family.

It would be important to charter other childhood adversities in addition to those covered in the present study. The better we manage to investigate the risk factors involved in the onset of eating disorders, the more efficiently we can concentrate our resources to those most in need of support. It would also be essential to establish whether there are critical periods during which the children or young adults in question would especially benefit from help and support.

\section{Competing Interests}

The authors declare that they have no competing interests.

\section{Authors' Contributions}

VS drafted the manuscript, conducted the literature search, analyzed all data and wrote the paper. MS and KM participated in the formulation of the aims of the study, in the interpretation of the main findings and in drafting the manuscript. All authors read and approved the final manuscript.

\section{Acknowledgements}

Kristiina Helander has made a substantial contribution to the translation process. Centre for General Practice, Pirkanmaa Hospital District has supported the work financially.

\section{References}

[1] Hoek, H.W. and van Hoeken, D. (2003) Review of the Prevalence and Incidence of Eating Disorders. International Journal of Eating Disorders, 34, 383-396. http://dx.doi.org/10.1002/eat.10222

[2] Hudson, J.I., Hiripi, E., Pope Jr., H.G. and Kessler, R.C. (2007) The Prevalence and Correlates of Eating Disorders in the National Comorbity Survey Replication. Biological Psychiatry, 61, 348-358. http://dx.doi.org/10.1016/j.biopsych.2006.03.040

[3] Mitchell, A.M. and Bulik, C.M. (2006) Eating Disorders and Women's Health: An Update. Journal of Midwifery \& Women's Health, 51, 193-201. http://dx.doi.org/10.1016/j.jmwh.2006.01.005

[4] Smink, F.R., van Hoeken, D. and Hoek, H.W. (2012) Epidemiology of Eating Disorders: Incidence, Prevalence and Mortality Rates. Current Psychiatry Reports, 14, 406-414. http://dx.doi.org/10.1007/s11920-012-0282-y

[5] Hoek, H.W. (2006) Incidence, Prevalence and Mortality of Anorexia Nervosa and Other Eating Disorders. Current Opinion in Psychiatry, 19, 389-394. http://dx.doi.org/10.1097/01.yco.0000228759.95237.78

[6] Gordon, K.H., Castro, Y., Sitnikov, L. and Holm-Denoma, J.M. (2010) Cultural Body Shape Ideals and Eating Disorder Symptoms among White, Latina, and Black College Women. Cultural Diversity \& Ethnic Minority Psychology, 16, 135-143. http://dx.doi.org/10.1037/a0018671

[7] Gard, M.C. and Freeman, C.P. (1996) The Dismantling of a Myth: A Review of Eating Disorders and Socioeconomic Status. International Journal of Eating Disorders, 20, 1-12. http://dx.doi.org/10.1002/(SICI)1098-108X(199607)20:1<1::AID-EAT1>3.0.CO;2-M

[8] Holland, L.A., Bodell, L.P. and Keel, P.K. (2013) Psychological Factors Predict Eating Disorder Onset and Maintenance at 10-Year Follow-Up. European Eating Disorders Review, 21, 405-410. http://dx.doi.org/10.1002/erv.2241

[9] Dalle, G.R. (2011) Eating Disorders: Progress and Challenges. European Journal of Internal Medicine, 22, $153-160$. http://dx.doi.org/10.1016/j.ejim.2010.12.010

[10] Chapman, D.P., Whitfield, C.L., Felitti, V.J., Dupe, S.R., Edwards, V.J. and Anda, R.F. (2004) Adverse Childhood Experiences and the Risk of Depressive Disorders in Adulthood. Journal of Affective Disorders, 82, 217-225. http://dx.doi.org/10.1016/j.jad.2003.12.013

[11] Jokela, M., Keltikangas-Järvinen, L., Kivimäki, M., Puttonen, S., Elovainio, M., Rontu, R. and Lehtimäki, T. (2007) 
Serotonin Receptor 2A Gene and the Influence of Childhood Maternal Nurturance on Adulthood Depressive Symptoms. Archives of General Psychiatry, 64, 356-360. http://dx.doi.org/10.1001/archpsyc.64.3.356

[12] Felitti, V.J., Anda, R.F., Nordenberg, D., Williamson, D.F., Spitz, A.M., Edwards, V., Koss, M.P. and Marks, J.S. (1998) Relationship of Childhood Abuse and Household Dysfunction to Many of the Leading Causes of Death in Adults. The Adverse Childhood Experiences (ACE) Study. American Journal of Preventive Medicine, 14, 245-258. http://dx.doi.org/10.1016/S0749-3797(98)00017-8

[13] Dinwiddie, S., Heath, A.C., Dunne, M.P., Bucholz, K.K., Madden, P.A., Slutske, W.S., Bierut, L.J., Statham, D.B. and Martin, N.G. (2000) Early Sexual Abuse and Lifetime Psychopathology: A Co-Twin-Control Study. Psychological Medicine, 30, 41-52. http://dx.doi.org/10.1017/s0033291799001373

[14] Korkeila, J., Vahtera, J., Korkeila, K., Kivimäki, M., Sumanen, M., Koskenvuo, K. and Koskenvuo, M. (2010) Childhood Adversities as Predictors of Incident Coronary Heart Disease and Cerebrovascular Disease. Heart, 96, 298-303. http://dx.doi.org/10.1136/hrt.2009.188250

[15] Sumanen, M., Rantala, A., Sillanmäki, L. and Mattila, K. (2007) Childhood Adversities Experienced by Working-Age Migraine Patients. Journal of Psychosomatic Research, 62, 139-143. http://dx.doi.org/10.1016/j.jpsychores.2006.08.010

[16] Wainwright, N.W., Surtees, P.G., Wareham, N.J. and Harrison, B.D.W. (2007) Psychosocial Factors and Asthma in a Community Sample of Older Adults. Journal of Psychosomatic Research, 62, 357-361. http://dx.doi.org/10.1016/j.jpsychores.2006.10.013

[17] Johnson, J.G., Cohen, P., Kasen, S. and Brook, J.S. (2002) Childhood Adversities Associated with Risk for Eating Disorders or Weight Problems during Adolescence or Early Adulthood. The American Journal of Psychiatry, 159, 394400. http://dx.doi.org/10.1176/appi.ajp.159.3.394

[18] Korkeila, K., Suominen, S., Ahvenainen, J., Ojanlatva, A., Rautava, P., Helenius, H. and Koskenvuo, M. (2001) NonResponse and Related Factors in a Nation-Wide Health Survey. European Journal of Epidemiology, 17, 991-999. http://dx.doi.org/10.1023/A:1020016922473

[19] Suominen, S., Koskenvuo, K., Sillanmäki, L., Vahtera, J., Korkeila, K., Kivimäki, M., Mattila, K.J., Virtanen, P., Sumanen, M., Rautava, P. and Koskenvuo, M. (2012) Non-Response in a Nationwide Follow-Up Postal Survey in Finland: A Register-Based Mortality Analysis of Respondents and Non-Respondents of the Health and Social Support (HeSSup) Study. BMJ Open, 2, e000657. http://dx.doi.org/10.1136/bmjopen-2011-000657

[20] Beck, A.T., Ward, C.H., Mendelson, M., Mock, J. and Erbaugh, J. (1961) An Inventory for Measuring Depression. Archives of General Psychiatry, 4, 561-571. http://dx.doi.org/10.1001/archpsyc.1961.01710120031004

[21] Gowers, S.G., North, C.D., Byrum, V. and Waever, A.B. (1995) Life Event Precipitants of Adolescent Anorexia Nervosa. Journal of Child Psychology and Psychiatry, 37, 469-477. http://dx.doi.org/10.1111/j.1469-7610.1996.tb01428.x

[22] Kotler, L.A., Cohen, P., Davies, M., Pine, D.S. and Walsh, B.T. (2001) Longitudinal Relationships between Childhood, Adolescent, and Adult Eating Disorders. Journal of the American Academy of Child \& Adolescent Psychiatry, 40, 14341440. http://dx.doi.org/10.1097/00004583-200112000-00014

[23] Hafstad, G.S., von Soest, T. and Torgersen, L. (2013) Early Childhood Precursors for Eating Problems in Adolescence: A 15-Year Longitudinal Community Study. Journal of Eating Disorders, 1, 35. http://dx.doi.org/10.1186/2050-2974-1-35

[24] Fuemmeler, B.F., Dedert, E., McClernon, F.J. and Beckham, J.C. (2009) Adverse Childhood Events Are Associated with Obesity and Disordered Eating: Results from a US Population-Based Survey of Young Adults. Journal of Traumatic Stress, 22, 329-333. http://dx.doi.org/10.1002/jts.20421

[25] Keski-Rahkonen, A., Hoek, H.W., Susser, E.S., Linna, M.S., Sihvola, E., Raevuori, A., Bulik, C.M., Kaprio, J. and Rissanen, A. (2007) Epidemiology and Course of Anorexia Nervosa in the Community. The American Journal of Psychiatry, 164, 1259-1265. http://dx.doi.org/10.1176/appi.ajp.2007.06081388

[26] Keski-Rahkonen, A., Raevuori, A., Bulik, C.M., Hoek, H.W., Sihvola, E., Kaprio, J. and Rissanen, A. (2013) Depression and Drive for Thinness are Associated with Persistent Bulimia Nervosa in the Community. European Eating Disorders Review, 21, 121-129. http://dx.doi.org/10.1002/erv.2182

[27] Gunnar, M. and Quevedo, K. (2007) The Neurobiology of Stress and Development. Psychology-Annual Review of Psychology, 58, 145-173. http://dx.doi.org/10.1146/annurev.psych.58.110405.085605

[28] Epel, E.S., Blackburn, E.H., Lin, J., Dhabhar, F.S., Adler, N.E., Morrow, J.D. and Cawthon, R.M. (2004) Accelerated Telomere Shortening in Response to Life Stress. Proceedings of the National Academy of Sciences of the United States of America, 101, 17312-17315. http://dx.doi.org/10.1073/pnas.0407162101 


\section{Abbreviations}

BED: Binge Eating Disorder; BDI: Beck’s Depression Inventory; BMI: Body Mass Index; CI: Confidence Interval; ED: Eating Disorder; HeSSUp: Health and Social Support Study; OR: Odds Ratio. 